\title{
Cuidado integral: concepções e práticas de docentes de Enfermagem
}

\author{
Integral care: conceptions and practices of Nursing professors
}

Cuidado integral: concepciones y prácticas de docentes de Enfermería

\author{
Margarete de Castro', Wilza Rocha Pereira" \\ ' Universidade Federal de Mato Grosso. Mestranda do Programa de Pós-Graduação em Enfermagem. Cuiabá- MT, Brasil. \\ " Universidade Federal de Mato Grosso. Faculdade de Enfermagem (FAEN/UFMT). Cuiabá- MT, Brasil.
}

Submissão: 17/02/2010Ａprovação: 07/11/2010

\begin{abstract}
RESUMO
A pesquisa teve o objetivo de compreender as concepções de um grupo de docentes sobre cuidado integral em saúde em um curso de Enfermagem e como estas se refletem nas suas práticas pedagógicas cotidianas. Foi um estudo de natureza qualitativa que teve como sujeitos 12 docentes de Enfermagem. A técnica de coleta de dados foi a entrevista e, para interpretar os dados, utilizamos a análise de conteúdo, na modalidade da análise temática. Os resultados apontam que há convergências discursivas sobre cuidado integral entre os docentes e, como um importante aspecto do estudo, vimos que este é um eixo que se afirma no curso e que vem permitindo novas formas de pensar o ensino de Enfermagem na realidade estudada.

Descritores: Educação em Enfermagem; Educação superior; Assistência Integral à Saúde.
\end{abstract}

\begin{abstract}
The research aimed to understand the conceptions of a group of professors about integral health care in a nursing course and how they influence their pedagogical practices. It was a qualitative study that had as subjects 12 nursing professors. The data collection technique used was the interview and to analyze it, we used content analysis, in its thematic analysis form. The results showed that there are discursive convergences about integral care amongst the professors, and as an important part of the study, we could see that it is an "axis" that is establishing itself in the course and that has been developing new forms of thinking about the way nursing is being taught, in the reality that was studied.
\end{abstract}

Key words: Education in Nursing; Higher Education; Comprehensive Health Care.

\section{RESUMEN}

La pesquisa tuve el objetivo de comprehender las concepciones de un grupo de docentes sobre cuidado integral en salud en un curso de grado en enfermería y como esas se reflejen en sus prácticas pedagógicas cotidianas. Fue una investigación de naturaleza cualitativa que tuve como sujetos 12 docentes de enfermería. La técnica de recolección de datos fue la encuesta abierta y para la interpretación de los datos utilizamos el análisis de contenido, en la modalidad de análisis temática. Los resultados dicen que tenemos convergencias discursivas sobre cuidado integral entre los docentes y, como un importante aspecto del estudio, vimos que es un eje que se afirma en el curso, lo que permite nuevas maneras de pensar la enseñanza de Enfermería en la realidad estudiada.

Descriptores: Educación en Enfermería, Educación Superior, Atención Integral de Salud. 


\section{INTRODUÇÃO}

Dada a polissemia que aporta a palavra cuidado, delimitamos, inicialmente, neste artigo, a nossa compreensão desse conceito, pois o vimos a partir de um contexto específico, que é a educação e a formação em Enfermagem. Nesse espaço, onde ocorrem práticas pedagógicas voltadas para o aprendizado do cuidado humano, há três sujeitos, com necessidades diferenciadas: o discente de Enfermagem, um aprendiz do cuidado; o docente, que ensina o cuidado; e o usuário do serviço de saúde, que recebe o cuidado desse aprendiz. Este último, por sua vez, tem a sua ação cuidativa constantemente mediada pelo docente.

É nosso entendimento, ainda, que as práticas pedagógicas mais consistentes no ensino de Enfermagem devem ter como centro aprender a cuidar do outro de uma maneira singular e integral. As práticas de cuidado que buscamos valorizar e que emergiram como concepções nas falas dos docentes, foram aquelas que apontavam para a idéia do acolhimento, da resolutividade e da formação de vínculo, indo além do atendimento às necessidades biológicas e mais imediatas e alcançando a compreensão de necessidade que o usuário do serviço expressa no processo relacional que aproxima o cuidador e sujeito cuidado.

É dentro desse processo relacional, onde acontece o cuidado, que percebemos que o ensino, quando adequadamente conduzido, pode fazer emergir a sensibilidade no discente, fundamental para sua formação como enfermeira(o) na atenção integral à saúde do usuário do SUS. Ficou claro ainda que compete ao docente pensar as suas práticas pedagógicas de tal maneira que estas possam favorecer o despertar da sensibilidade no aluno, de modo que este pense o cuidado como um valor humano e como o objeto primeiro da ação em Enfermagem.

O processo educativo, tal como o processo de cuidar, é um trabalho que acontece sempre no âmbito das relações interpessoais, sempre em interação. Para melhor compreendermos as concepções dos docentes de Enfermagem sobre o cuidado integral, pensamos no ensino e em práticas pedagógicas adequadas como aquelas providas de elementos que não só caracterizam, mas que dão sentido ao cuidar do outro e, ao mesmo tempo, reafirmam a identificação do aluno com a profissão e com o Sistema Único de Saúde (SUS), lócus privilegiado onde ocorrem todas as práticas de ensino desenvolvidas no curso onde foi feito o estudo.

O SUS traz em seus princípios vários elementos que perpassam o conceito de cuidado integral, e vários deles estão descritos no Programa Nacional de Humanização (HumanizaSUS). Este programa aponta vários elementos que compõem o cuidado integral, sendo que o primeiro deles é o acolhimento, que traz em si a idéia de resolutividade e, também, de responsabilização. O acolhimento é

[...] um modo de operar os processos de trabalho em saúde de forma a atender a todos que procuram os serviços de saúde, ouvindo seus pedidos e assumindo no serviço uma postura capaz de acolher, escutar e pactuar respostas mais adequadas aos usuários. Implica prestar um atendimento com resolutividade e responsabilização, orientando, quando for o caso, o paciente e a família em relação a outros serviços de saúde para a continuidade da assistência e estabelecendo articulações com esses serviços para garantir a eficácia desses encaminhamentos ${ }^{(1)}$.

A resolutividade traz implícita a articulação que o trabalhador deve fazer com os outros serviços de saúde para a continuidade da atenção a esse outro, o usuário do serviço. Articulação essa quase sempre é mais facilitada por quem está dentro do serviço e conhece os entremeios dos encaminhamentos que permitem atender ao outro e à sua saúde de forma integral.

Assim as idéias de relacionalidade, de interação entre pessoas, de acolhimento, de responsabilização, a escuta atenta, são elementos que deverão fazer parte do olhar do docente, no momento de pensar e colocar suas práticas pedagógicas em ação nos diferentes contextos onde se produz saúde.

O espaço do cuidado se estabelece através da empatia entre ambos, sujeito que cuida e sujeito que é cuidado, e se realiza através da escuta atenta e de ações concretas. A mediação deste encontro se dá através do conhecimento como "ferramenta" do primeiro, o trabalhador de saúde, e pela necessidade do segundo, o usuário do serviço.

$\mathrm{O}$ professor que ensina ao futuro enfermeiro o trabalho em saúde precisa ter a sensibilidade de (ao colocar o aluno/ aprendiz frente a frente com um usuário-sujeito com necessidades de saúde) trabalhar práticas pedagógicas que deixem claro que este é um encontro entre seres humanos, e que ele - o docente - é, de certa forma, o mediador desse encontro, pois se supõe que detém o conhecimento que o aluno de Enfermagem ainda está construindo/aprendendo. O aluno é um aprendiz e, como tal, não tem ainda a dimensão da complexidade que o cuidado exige para realmente ser integral.

Nesse encontro entre aluno e sujeito cuidado, muitas vezes, se não houver a mediação do professor, o discente não percebe as diferentes maneiras de ampliar seu ato cuidativo e pode torná-lo mais técnico e menos integral. Pequenas ações, formas de tocar ou de se comunicar, esclarecer ao sujeito cuidado o que se faz, porque se faz dessa forma, como ele pode colaborar, dão qualidade e aumentam a satisfação daquele que precisa ser cuidado e, também, exigem do professor uma atenção ao aluno que está sob sua supervisão. Ele também é um sujeito a ser cuidado, pois a proximidade física e emocional, que $o$ ato de cuidar exige, pode inibir o discente e tornar o processo de cuidar mais árduo; e o professor é aquele que facilita essa aproximação e faz a mediação entre o aprendiz e o sujeito cuidado, garantindo que, se houver algum impedimento por parte do aluno, ele assume o cuidado e pode finalizá-lo.

Quando um usuário do serviço se 'entrega' a um cuidador que ainda é um aprendiz, este último desconhece as razões e sentimentos que trouxeram aquele sujeito ao serviço. Temos, então, uma situação de desequilíbrio, de habilidades e expectativas diferenciadas onde um - o usuário - busca assistência, em estado físico e emocional frequentemente fragilizado, junto ao outro - um profissional supostamente capacitado 
para atendê-lo e cuidar do outro. O docente deve estar atento para que se crie um vínculo entre ambos, pois se conseguir esta sensibilização do aprendiz ao cuidar do outro, neste momento ele pode estar gerando a ligação afetiva, traduzida pelo respeito não só entre ambos, mas neste encontro ele está propiciando ao aluno a identificação com o objeto primeiro da nossa prática cotidiana, que é cuidar do outro e estar sensível e de prontidão para atender às suas necessidades. Assim, o cuidado humano é

[...] uma atitude ética em que seres humanos percebem e reconhecem os direitos uns dos outros. [...] consiste em uma forma de viver, de ser, de se expressar. É uma postura ética e estética frente ao mundo. É um compromisso com o estar no mundo e contribuir com o bem estar geral, na preservação da natureza, na promoção das potencialidades e da dignidade humana e da nossa espiritualidade; é contribuir na construção da historia, do conhecimento, da vida ${ }^{(2)}$.

Mesmo que o docente consiga a sensibilização do aprendiz no cuidado para com o outro, este deve estar atento quanto às múltiplas faces que o cuidado apresenta, dentre elas, a técnico-científica que, por vezes, se sobrepõe às demais e ao próprio sujeito que vem em busca de ajuda, ou seja,

[...] ainda que o cuidado assuma tal importância na construção dessa identidade profissional, as práticas têm privilegiado o estabelecimento de procedimentos cada vez mais complexos, em detrimento da valorização do sujeito na construção de um cuidado integral(3).

A consideração acima nos parece pertinente, uma vez que o cuidado se constitui no principal elo entre todas as profissões de saúde, tanto que ao nos referirmos sobre a adoção de modelos que priorizam o cuidado, acreditamos que a "troca de experiências entre docentes e a constante atualização parecem ser sugestões pertinentes, pois sempre é necessário buscar meios que valorizem o cuidado humano" (4). O primeiro passo a ser dado neste sentido é a criação de "um ambiente de cuidado onde as relações de cuidado sejam cultivadas"(4:).

Por relação de cuidado entende-se o relacionamento entre pessoas que exibem comportamentos de cuidar que são aqueles

[...] que se distinguem pela expressão de comportamentos de cuidar, que as pessoas compartilham, como confiança, respeito, consideração, interesse, atenção, entre outros... Em um ambiente de cuidado, as pessoas sentem-se bem, reconhecidas e aceitas como são; conseguem se expressar de forma autêntica e se preocupam umas com as outras no sentido de atualizar informações, fornecendo e trocando idéias, oferecendo apoio e ajuda e se responsabilizando e comprometendo com a manutenção desse clima de cuidado(5).

Para que se estabeleça uma relação de ensino entre docente e discente, é necessário que haja, por parte do docente, uma intenção e uma predisposição para ensinar. Pois ensinar é
[...] reforçar a idéia de aprender, sem agir como se ela estivesse tomada de uma vez por todas. É não encerrar o aluno em uma concepção do ser sensato e responsável, que não convém nem mesmo à maior parte dos adultos. É [...] estimular o desejo de saber ${ }^{(6)}$.

O aprendiz, por sua vez, apresenta uma atitude responsiva, que pode variar segundo a forma como é iniciada a relação, através de ações, atitudes e comportamentos por parte do docente. A percepção da presença real de ambos envolvidos no processo de aprender permitirá que no processo de ensino/ aprendizado haja maior engajamento por parte do aprendiz e este passa a responsabilizar-se mais pelo seu próprio aprendizado.

\section{PERCURSO TEÓRICO METODOLÓGICO}

Trata-se de uma pesquisa descritiva e exploratória, com abordagem qualitativa, desenvolvida em um Curso de Enfermagem de uma universidade pública de Mato Grosso, após a aprovação no Comitê de Ética em Pesquisa do Hospital Universitário Júlio Müller (Parecer no 315/CEP/HUJM/07). Atendemos todas as determinações da Resolução no 196/96 do Conselho Nacional de Pesquisa (CONEP) e todos os participantes do estudo assinaram o Termo de Consentimento Livre e Esclarecido, depois de conhecer os objetivos e finalidades do estudo(7). O anonimato e o sigilo dos participantes foram garantidos.

Os critérios adotados para a seleção dos sujeitos do estudo foram: ser docente efetivo do curso estudado; estar no exercício da docência há mais de 01 (um) ano na ocasião da coleta de dados; ser enfermeiro e aceitar participar da pesquisa; e assinar o Termo de Consentimento Livre e Esclarecido. Tivemos 12 docentes do Curso de Enfermagem que aceitaram participar do estudo, sendo $16 \%$ do sexo masculino e $84 \%$ do sexo feminino.

Os dados foram coletados no período de maio a julho de 2009 por meio da técnica da entrevista aberta e individual acompanhada de um roteiro norteador para aprofundar aspectos de relevância para a pesquisa. Como estratégias utilizadas para coletar os dados, foi encaminhado, inicialmente, convite a todos docentes, via e-mail, apresentando os objetivos e as finalidades da pesquisa. À medida em que houve aceitação por parte destes, foi feito agendamento prévio, especificando e entrando em acordo com o sujeito do estudo a data, horário e o local de sua preferência para a entrevista. Foram considerados critérios para encerrar as entrevistas a "saturação" dos dados, que se caracteriza pela "repetição de conteúdos relativos aos problemas investigados" nas entrevistas que sucederam ${ }^{(8)}$.

Após a coleta de dados e as transcrições das fitas, os dados foram organizados seguindo os seguintes passos: primeira ordenação, classificação por temas e análise final. Na fase de ordenação, procedeu-se à organização inicial dos dados por meio da leitura exaustiva de cada entrevista individual e depois do conjunto de todas que foram feitas. Nesse processo encontramos os núcleos de sentido e formamos os grandes temas e os classificamos de acordo com sua repetição 
e similaridade com os conceitos sobre cuidado integral em saúde. Em seguida fizemos nova leitura do material, para apreender, nas descrições das falas, as estruturas de relevância encontradas nos relatos dos docentes. Esses dados foram submetidos a análise de conteúdo, na modalidade de análise temática, quando então interpretamos os dados em um constante diálogo com os conceitos base que deram sustentação ao estudo ${ }^{(8)}$.

Para facilitar a apresentação dos resultados, as unidades nucleadoras, encontradas nos discursos dos docentes, foram registradas em letra estilo itálico, identificadas com uma letra, seguida de um número, como por exemplo, D-1. A letra D corresponde ao docente participante do estudo e o número, representa a ordem da realização das entrevistas.

\section{RESULTADOS E DISCUSSÃO}

Percebemos ao longo das entrevistas realizadas com os docentes a concepção de cuidado integral é um elemento fundamental para uma prática de Enfermagem de qualidade. Essa prática deverá ser "capaz de formar profissionais imbuídos de práticas cuidadoras em saúde, com respeito à pluralidade e à singularidade dos processos de viver a vida" (9:9). Essa pluralidade pode ser encontrada no depoimento do docente abaixo, quando explicita a sua compreensão sobre a integralidade do cuidado.

[...] o sujeito, ele precisa ser visto na sua integralidade, o que significa pra mim que a gente não tem que preocupar na saúde só com as necessidades que são individualizadas, orgânicas... [estas são] uma das dimensões do ser humano, a dimensão orgânica. Mas [...] as necessidades, elas têm outras naturezas também, necessidades psicoemocionais, necessidades socioculturais que precisam ser consideradas no âmbito do cuidar e do ensinar. (D-9)

Outros aspectos sobre o cuidado integral são importantes e o docente D4 faz uma apropriação entre o que entende por cuidado integral e as formas de articulação que ele exige.

\section{[...] eu entendo o cuidado integral em saúde como produto} do trabalho de muitos, de vários profissionais de saúde, não acho que seja produto do trabalho exclusivo do enfermeiro ou da Enfermagem. Especial porque articula, tem objetivos comuns, é onde estabelece processo de comunicação, a interação em torno de um processo de trabalho. (D-9)

O "desenvolvimento do pensamento crítico envolve um processo longo de reflexão que implica na introspecção pessoal, o que nem sempre é fácil para a maioria das pessoas"(10), pois compõe-se de "atitudes, habilidades e conhecimento e traz uma grande dependência do contexto"(10) ${ }^{\prime \prime}$ de se desenvolve a ação. Como lembra essa docente:

Bom, [sobre] o cuidado integral na formação do enfermeiro, eu acredito na possibilidade de que nós, enquanto docentes, devemos levar o aluno a entender um cuidado de Enfermagem voltado não apenas para a questão biológica, [para] o corpo doente, o tratamento, ou direcionado a uma doença, [...] mas também que ele [o aluno] possa ter a possibilidade de entender os indivíduos, suas famílias, o seu contexto social, [possa perceber] como a pessoa está inserida no mercado de trabalho, como é a sua renda, como é a sua escolaridade, como esses fatores estão fortalecendo a saúde ou como eles estão desgastando a pessoa e facilitando o desenvolvimento de uma doença. (D-04)

As concepções de cuidado que estão subjacentes às falas acima remetem ao sujeito do cuidado como um ser de necessidades diversas e diferenciadas, nas quais se sobressaem as necessidades de natureza psicoemocional, sociocultural, educacional, econômica, todas podem associar-se e facilitar 'o desenvolvimento de uma doença'. Este depoimento da D4 lembra que a complexidade do cuidado integral remete à complexidade da existência, do viver a vida cotidiana, onde uma necessidade não satisfeita pode interferir em todas as outras e expor o sujeito de forma a torná-lo mais vulnerável socialmente e com isso torná-lo mais suscetível ao adoecimento. Essa perspectiva lembra que as necessidades de saúde são

[...] busca de algum tipo de resposta para as más condições de vida que a pessoa viveu ou está vivendo (do desemprego à violência no lar), a procura de um vínculo afetivo com algum profissional, a necessidade de ter maior autonomia no modo de andar a vida ou, mesmo, de ter acesso a alguma tecnologia de saúde disponível, capaz de melhorar ou prolongar sua vida ${ }^{(11)}$.

O sujeito que cuida, ao acolher o outro e respeitar sua cultura, limites, entorno social, reafirma-se com um sujeito cuidador. Isto se dá dentro de um processo relacional com o sujeito que é cuidado, pois ele - cuidador - precisa compreender e se aproximar da realidade da pessoa cuidada, para, saber que, quem está ali,

[...] é uma pessoa, não é apenas uma perna, não é apenas um braço, é uma pessoa com sentimentos, com prazeres, com dores, com direitos, com deveres. (D-10)

Ser docente de Enfermagem implica dominar várias competências das quais muitas estão na área pedagógica e outras na área específica de conhecimento que é a Enfermagem. Para que possamos ensinar alguém a cuidar de outrem, precisamos reaprender continuamente a cuidar, pois o cuidado exige esta atitude ativa, mas precisamos também e todos os dias reaprender a ser professor. Esta última atividade implica em um amplo rol de competências que não nos foi ensinado na vida acadêmica, mas que dela nos apropriamos por necessidade e com algumas dificuldades, que acabam por ser contornadas com estudo de autores da área da pedagogia, como diz a depoente:

[...] procuro trabalhar na minha prática pedagógica, com alguns autores como o Contreras, ...ele traz [a idéia] de que o aluno quando ele tem autonomia, ele aprende 
melhor! Ele se sente responsável pelo seu aprendizado! É diferente quando você transmite pra ele tudo àquilo que você acha que é mais importante... assim você não dá autonomia para o aluno. (D-03)

Nesse sentido, o professor é alguém que estando mais adiantado no processo de aprendizagem e dispõe de conhecimentos e práticas sempre renovados sobre a aprendizagem, assim se tornaria capaz de cuidar da aprendizagem na sociedade e pode melhor garantir aos alunos o direito de aprender (12demo). Seguindo essa linha de pensamento o docente abaixo assim se expressa:

[...] nas aulas que eu tenho dado, tenho procurado fazer o aluno pensar como que está a nossa sociedade hoje, como está a dinâmica de trabalho e da vida mesmo [...] que acesso as pessoas estão tendo aos alimentos, não só por questões econômicas, mas como a mídia tem interferido nisso, como que a globalização das coisas e da vida tem influenciado as pessoas a desenvolver alguns tipos de hábitos. (D-04)

Ao reportar-se aos modos de vida impostos pela globalização e definir esta como um fenômeno que interfere e induzem novos modos de viver que podem ser prejudiciais ao ser humano, o docente lembra que está falando como um formador, que precisa ampliar a visão que o discente tem sobre os processos que nos levam ao adoecimento, que podem estar no modo de vida, de consumo, de compreensão do que nos diz a mídia, pois "ensinar exige reflexão crítica sobre a prática, em um movimento dinâmico e dialético entre o fazer e o pensar sobre esse fazer"(13). O docente lembra que o meio é um vetor poderoso de indução de novos hábitos, que acabam por ser prejudiciais a nossa saúde, não podendo, jamais, ser ignorados no processo de cuidar em Enfermagem.

A reflexão sobre as diferentes maneiras de viver, que podem ser ou não saudáveis, aparece também no depoimento a seguir, no qual o docente insiste sobre o aprender reflexivo, que ajude o discente a pensar na importância de que suas ações nunca sejam apenas de reproduzir conhecimentos, mas de criação, de conexão com o outro e seu mundo.

[...] nas minhas aulas práticas [eu tenho] buscado introduzir os alunos [para que] percebam que o que eles estão fazendo não é simplesmente uma atividade mecânica, mas sim algo que precisa ser refletido, que tem uma razão de ser. E também o conhecimento científico [que deve] embasar seu procedimento, [e além disso] nós precisamos olhar para o sujeito enquanto sujeito integrado, como um todo, [que] não tem só cabeça, tronco e membros, mas que está inserido numa sociedade, que está com seus problemas econômicos, que tem uma cultura, que tem um conhecimento. (D-08)

O educador deve voltar-se para si mesmo, refletir e adotar uma postura de questionamento tanto sobre sua formação como precisa também conscientizar-se de que esta deve ser permanente e contínua e acompanhar todas as transformações da realidade ${ }^{(13: 93)}$. Este olhar crítico e reflexivo sobre a prática atual ou a passada é o que ajuda e a melhorar a próxima prática pedagógica. Essa concepção está inserida no relato seguinte:

[...] a cada ano você vai repensando suas práticas, vai repensando em como você pode melhorar, o que você pode modificar, porque eu vejo hoje, que quando se fala em pedagogia moderna ou pós-moderna, as pessoas estão confundindo muitas coisas. Então, muita gente está achando que hoje ser um professor moderno não é mais você partilhar conhecimento com aluno, é você sempre jogar pro aluno buscar [...] E não foi isso que Paulo Freire quis dizer quando ele criou a pedagogia do oprimido, mas sim construir juntos (D-02).

Assim, ao refletirmos continuamente sobre o nosso fazer cotidiano como docentes podemos melhor aproveitá-los para a melhoria de nosso fazer.

A “autonomia e a responsabilidade de um profissional dependem de uma grande capacidade de refletir em e sobre sua ação" ${ }^{(14)}$. O docente valoriza a reflexão sobre a ação realizada quando promove a discussão das atividades realizadas diariamente, conforme ilustra o relato:

[...] Sempre no final das atividades, eu sento aqui com eles [alunos] na sala de reuniões, e a gente discute o que eles vivenciaram naquele dia e a gente tem trabalhado muito nesse sentido[...] (D-4)

O desenvolvimento do pensamento crítico "envolve um processo longo de reflexão que implica na introspecção pessoal, o que nem sempre é fácil para a maioria das pessoas"(14), mas a prática pedagógica, tal como o processo de cuidar, é um trabalho que acontece sempre no âmbito das relações interpessoais. Sendo assim, as mesmas devem ocorrer sempre em interação, e essa favorece esse processo de estar juntos para o aprendizado do cuidado ao outro.

O docente, quando traz o conhecimento teórico e o aplica, o torna mais inteligível ao aluno e isso acontece mais nas práticas de estágio. Nesse movimento de ensinar a cuidar do outro e cuidando também do aluno, para que ele não se contamine, que fique mais relaxado, dando-lhe mais segurança para o cuidado, permite ao aprendiz vivenciar o que é ser cuidado pelo docente que cuida não só da aprendizagem dele, aluno, mas também dele, pessoa que está aprendendo, que precisa de tolerância e paciência por parte do docente. Nesse processo, o docente cria a ambiência necessária ao aprendizado sobre o cuidado do outro, que é a finalidade do curso de Enfermagem.

[...] eu sempre trago essa disciplina pra realidade local, pra realidade do campo de prática, pra realidade na qual o aluno está inserido, sem esquecer do aluno. Então, eu entendo que, essa contextualização da teoria com a prática vigente, é que vai transformar esse cuidado, porque o ensino é como Waldow diz, ele faz parte do construto 
do cuidado, quando você está compartilhando o conhecimento com alguém, você também está cuidando! (D-02).

Assim, ao pensarmos em ensino e práticas pedagógicas adequadas, eficientes e éticas, precisamos pensar nos elementos que caracterizam e dão sentido ao cuidar do outro também, desde a perspectiva das políticas públicas que estão postas para os serviços de saúde e que precisam ser ensinadas aos futuros enfermeiros. Um desses elementos é o acolhimento que, como política e programa, pode ser visto em sua inteireza no Programa Nacional de Humanização - Humaniza SUS ${ }^{(1)}$. Este diz que acolher é receber o usuário desde a sua chegada ao serviço, responsabilizar-se integralmente por ele, ouvir suas queixas, permitir que ele expresse suas preocupações, angústias, praticando a escuta atenta do que o aflige. Essa concepção aparece no depoimento do docente D8, a seguir.

[...] precisamos estar atentos a outras dimensões desse cuidar, não só as doenças em si ou as partes que estão envolvidas nesse processo de doença, ou que passaram por algum procedimento, mas quem está sendo atendido ali [é] um sujeito que tem medos, que tem ansiedades, que é pai de família, que é mãe de família, que deixou um filho em casa, que precisa voltar ao trabalho... (D-8).

Como diretriz para a apreensão do cuidado integral, podemos entender que este é também uma "ação técnico-assistencial que pressupõe a mudança da relação profissional/usuário e sua rede social através de parâmetros técnicos, éticos, humanitários e de solidariedade, reconhecendo o usuário como sujeito e participante ativo no processo de produção da saú$\mathrm{de}^{\prime \prime(15)}$. Mas esta ação precisa ser complementada com outros elementos, que vão dar um sentido mais humanizador ao cuidado, que não pode ser visto apenas como uma ação 'técnica e assistencial'. O acolhimento é um desses elementos e, nas práticas de produção em saúde, pode ser entendido como ato ou efeito de acolher que expressa, em suas várias definições, uma ação de aproximação, um "estar com" e um "estar perto de", ou seja, uma atitude de inclusão(16).

O docente, ao adotar práticas de ensino e práticas de cuidar próprias, como enfermeiro-docente que é, valoriza os múltiplos elementos que se somam e que compõem o cuidado integral ao usuário. Nesse movimento, ao mostrar-se ao aprendiz como sujeito cuidador, ele ajuda o aluno no seu processo de formação valorizando atitudes de aproximação com o outro, acolhendo esse outro nas suas necessidades de saúde e também apoiando os familiares dos sujeitos que são por eles cuidados. Podemos ver essa preocupação na fala da depoente 1 [...] como eu trabalho com crianças, a gente passa a ver [tanto] a doença que afetou a criança como a criança afetada, [vê] ainda o cuidador afetado [que na pediatria] é a mãe, o pai ou o responsável (D-1).

Assim, todos os elementos do cuidado integral podem ser 'transferidos', amalgamados, juntados e vir a somar-se quando alguém de uma família adoece, ela adoece junto, suas rotinas mudam, seu tempo para si muda, os sentidos ficam voltados para aquele que está doente. $\mathrm{O}$ aluno, como aprendiz de cuidador, precisa ter clara essa dimensão do cuidar que se estende por toda a família e, não raro, também pela equipe de Enfermagem.

Na internação pediátrica é comum o envolvimento de toda a equipe que, ao cuidar integralmente e cotidianamente de crianças doentes, acaba por sensibilizar-se com os problemas que as afetam e também à sua família. Formam assim vínculos que vão além do cuidado técnico com a família e a criança. Na realidade onde realizamos esse estudo o vínculo que extrapola o espaço do cuidado e leva a amizades duradouras entre cuidadores e pessoas cuidadas são mais comuns na área pediátrica do que nas outras áreas clínicas.

Há profissionais de Enfermagem procuram voltar para trabalhar comunidades onde aprenderam a ser enfermeiros. Temos casos de ex-alunos que foram absorvidos nas mesmas comunidades onde realizaram seus estágios curriculares.

Mas, da mesma forma que há alunos que se integram e retornam como trabalhadores aos locais onde fizeram seus estágios, há, também, momentos na prática pedagógica docente, de alguns alunos literalmente detestarem uma determinada clientela ou um espaço de prática. Nesse casos, relativamente frequentes, os docentes precisam de um especial sentido de alteridade para poder dar o apoio que o aluno precisa quando não há essa identificação imediata entre o discente e uma clientela ou uma determinada prática, pois o aluno na sua imaturidade, pode, por insegurança provocar iatrogenias no processo de cuidar. Nesses momentos, os docentes precisam recorrer a outras técnicas didático-pedagógicas, específicas para a área da saúde, para apoiar o aluno e fazer com que ele perceba que o cuidado ao humano extrapola o sentido individual de gostar ou não, se identificar ou não, pois o cuidar de um outro ser, igual a nós mesmos, portador dos mesmos direitos, exige um tipo de entrega singular, que não é comum em outras profissões, mas é ela que nos faz cuidadores genuínos.

Há outros momentos no processo de aprendizagem em que se trabalha com sofrimentos intensos e mesmo com o enfrentamento da morte. Para dar sentido ao ato de ensinar em Enfermagem e, ao mesmo tempo, construir um sujeito que seja sensível e solidário com o outro que sofre, sem perder a objetividade que muitas situações de agravamento de saúde exigem do enfermeiro, há necessidade de envolvimento e conhecimento especiais do docente de Enfermagem, que nem sempre estão claros nas teorias pedagógicas.

Estas modalidades de ensinar a enfrentar o sofrimento e a morte de um ser igual a nós mesmos exigem novos conhecimentos pedagógicos, e estes precisam ser recriados para o adequado exercício da docência em Enfermagem. São habilidades e competências que não estão claramente dadas nas atuais teorias pedagógicas; assim nós, docentes de Enfermagem, precisamos investir para produzir novos conhecimentos que nos ajudem a melhor conduzir o ensino na nossa área.

Tal como o usuário, o nosso aluno também precisa ser acoIhido, atendido, ouvido e ter respostas às suas necessidades, para tornar-se um profissional de saúde ético, solidário e corresponsável pelo outro que recebe o cuidado. Pressupomos que, quando somos/estamos ainda como alunos de um curso universitário - a depender de nosso nível de maturidade 
emocional - podemos introjetar valores, atitudes, maneiras de cuidar que venham muito mais reproduzir aquilo que o professor faz de fato, do que aquilo que ele diz ser importante fazer. No processo de ensino-aprendizagem se o docente não estiver atento às suas atitudes e práticas, ele pode estar mais 'deformando' do que formando pessoas, pois apreendemos valores quando os vemos concretizados através das ações, ou seja, docente ainda é um espelho no qual o discente se enxerga.

Concordamos que ensinar a cuidar inclui contribuir para o

crescimento do outro, reconhecer a sua independência e deixá-lo em liberdade, incluindo-se o da humildade, um dos elementos que exige do cuidador disponibilidade para aprender sobre o outro e sobre si mesmo, superar a pretensão, falsa modéstia e avaliar as próprias limitações e poderes $^{(19)}$.

Da mesma maneira, o docente genuinamente interessado no processo de ensinar em Enfermagem precisa desenvolver a paciência, um atributo da docência e um importante coadjuvante no processo de aprender a cuidar do outro. É fundamental permitir ao aluno crescer "em seu tempo e de sua maneira, ter tolerância com as suas muitas limitações, confusões e divagações, ser honesto e sincero" para com aquele que está aprendendo, pois a sinceridade é uma condição necessária para que o aprendiz valorize o que sabe e se abra para aprender o que ainda não sabe ${ }^{(17)}$.

A coragem, em fina mescla com a responsabilidade, é um componente importante na docência do cuidado, pois requer do docente-cuidador que este, muitas vezes, se lance no desconhecido e confie nas suas próprias capacidades de apoiar sem tirar as oportunidades de o aluno aprender. $\mathrm{O}$ docente de Enfermagem precisa estar ali, junto ao aluno, para ajudá-lo e apoiá-lo e, ainda que este erre, o professor precisa recorrer a sua sensibilidade para não reiterar no aprendiz o medo, mas sim que ele, o aluno, aproveite o erro para desenvolver a autoconfiança de se acreditar, como aluno que ainda é, estar em 'processo de' e isso lhe dá o direito de errar mas acrescenta ao professor a responsabilidade de complementar o cuidado, mostrando ao aluno que ele não é incapaz, mas esta ainda aprendendo a cuidar.

O ensino do cuidado exige esta complementaridade entre docente e discente e o erro nesta área do conhecimento precisa ser visto como em todas as outras, mas nela, ao docente compete não deixar que este erro prejudique o sujeito cuidado e o que esta aprendendo a cuidar. Por todas essas razões que as atividades de acompanhamento de práticas em Enfermagem exigem um número menor de alunos por professor que nas demais áreas, na razão de dez alunos para um professor.

A esperança e a confiança são aspectos essenciais no ato de ensinar a cuidar e, para essa atividade, é fundamental a capacidade de que o docente sempre acreditar nas potencialidades do aprendiz para ajudar no seu desenvolvimento como futuro cuidador. Isso precisa ser feito em concomitância com atitudes de apoio ao discente para que ele supere os próprios limites e cresça desenvolvendo a responsabilidade, a ética, o conhecimento e a autoconfiança, pontos em que docente genuinamente interessado e envolvido no processo de aprender do aluno de Enfermagem faz enormes diferenças.

Assim, finalizamos lembrando que o

fenômeno da aprendizagem, na relação pedagógica, contempla não só a informação, mas também aprende-se a (re)estabelecer uma relação entre quem ensina e aquilo que é ensinado. Ensina-se e aprende-se a refletir sobre a realidade, colocando-se frente a um conhecimento contextualizado, provocando mudanças nas formas de pensar, sentir e agir ${ }^{(18)}$.

\section{CONCLUSÃO}

O estudo teve como eixo central compreender as concepções sobre o cuidado integral dos docentes de Enfermagem e em como estas interferem na formação do enfermeiro. Ao iniciarmos este estudo tínhamos como pressuposto de que docente que domina a arte de cuidar, consegue cuidar tanto do aprendizado do aluno como do outro que o aluno esta aprendendo a cuidar, mas ao terminar o estudo pudemos perceber que ensinar em Enfermagem exige muito mais que o domínio das artes do cuidado, precisamos pensar em uma pedagogia para melhor ensinar a cuidar da vida e da morte, da dor e do sofrimento e esta ainda não está dada nas teorias pedagógicas tal como as conhecemos na atualidade.

O cuidado integral aporta muitos elementos que podem servir como base para se pensar estas novas pedagogias e novos projetos pedagógicos que nos ajudem no planejar e executar cotidiano do ensino em Enfermagem. Percebemos na vasta produção sobre o tema, que há um grande potencial nas teorizações sobre cuidado integral que podem apoiar o desenvolvimento de novos estudos sobre novas práticas pedagógicas em Enfermagem e saúde.

A competência pedagógica se revela na ação pedagógica docente, ou seja, caminhamos no sentido de reafirmar o professor de Enfermagem está condenado a aprender seu ofício na prática cotidiana reflexiva, já que cada sujeito que ensina é único e cada dia de ensino é absolutamente singular no mundo da saúde. A isso acrescentamos, já que falamos desde a Enfermagem: é no espaço concreto da prática profissional em Enfermagem que as competências para o cuidado são demonstradas, é no fazer que elas emergem, ou seja, é na prática que exercitamos nossas potencialidades e nelas também as atualizamos, sobre elas refletimos coletivamente e só assim as aperfeiçoamos. O ensinar em Enfermagem precisa ser cada vez mais reflexivo e coletivo, é através das trocas de experiências e da abertura dos processos de planejar e organizar o ensino aos discentes que poderemos criar as bases para uma pedagogia que possa contribuir para melhor ensinar em Enfermagem. 


\section{REFERÊNCIAS}

1. Ministério da Saúde. Secretaria-Executiva. Núcleo Técnico da Política Nacional de Humanização. Humaniza SUS: acoIhimento com avaliação e classificação de risco: um paradigma ético-estético no fazer em saúde/Ministério da Saúde, Secretaria-Executiva, Núcleo Técnico da Política Nacional de Humanização. Brasília (DF): Ministério da Saúde; 2004.

2. Waldow VR. O cuidado na saúde: as relações entre o eu, o outro e o cosmo. Petrópolis (RJ): Vozes, 2004.

3. Henriques RLM, Acioli S. A Expressão do cuidado no processo de transformação curricular da Faculdade de Enfermagem da Universidade do Estado do Rio de Janeiro. In: Pinheiro R, Ceccim RB, Mattos RA, organizadores. Cuidado: as fronteiras da integralidade. Rio de Janeiro: Hucitec, 2004. p. 293 - 305.

4. Waldow VR. Estratégias de ensino na Enfermagem: enfoque no cuidado e no pensamento crítico. Petrópolis (RJ): Vozes, 2005.

5. Waldow VR. O cuidado na saúde: as relações entre o eu, o outro e o cosmo. Petrópolis (RJ): Vozes, 2004.

6. Perrenoud P. Dez novas competências para ensinar: convite à viagem. Porto Alegre (RS): Artmed, 2000.

7. Ministério da Saúde. Conselho Nacional de Saúde. (BR). Resolução 196/96. Pesquisas com seres humanos. Brasília (DF): Ministério da Saúde; 1996. 44p.

8. Minayo MCS. O desafio do conhecimento: pesquisa qualitativa em saúde. 11a. ed. São Paulo (SP): Hucitec, 2008.

9. Pinheiro R, Ceccim RB, Mattos RA. Ensinar Saúde: Experienciação, formação, cuidado e conhecimento em saúde: articulando concepções, percepções e sensações para efetivar o ensino da integralidade. In: Pinheiro R, Ceccim RB, Mattos RA, (orgs). Ensinar Saúde: a integralidade e o SUS nos cursos de graduação na área da saúde. Rio de Janeiro: ABRASCO, 2005. p. 13-33.

10. Waldow VR. Cuidar/cuidado: o domínio unificador da Enfermagem. In: Waldow VR, Lopes MJM, Meyer D, (org).
Maneiras de cuidar, maneiras de ensinar: a Enfermagem entre a escola e a prática profissional. Porto Alegre: Artes Médicas, 1995. p. 7-30.

11. Cecílio LCO. As necessidades de saúde como conceito estruturante na luta pela integralidade e equidade na atenção em saúde. In: Pinheiro R, Mattos RA, organizadores. Os sentidos da integralidade na atenção e no cuidado à saúde. Rio de Janeiro: ABRASCO; 2001. p. 113-126

12. Demo P. Professor do Futuro e reconstrução do conhecimento. Petrópolis (RJ): Vozes, 2004

13. Lucchese R, Barros S. Pedagogia das competências - um referencial para a transição paradigmática no ensino de Enfermagem - uma revisão da literatura. Acta Paul Enferm 2006; 19 (1): 92-9.

14. Perrenoud P. Prática reflexiva no ofício de professor: profissionalização e razão pedagógica. Traduzido por Schilling C. Porto Alegre (RS): Artmed, 2002.

15. Ministério da Saúde. Secretaria-Executiva. Núcleo Técnico da Política Nacional de Humanização. Humaniza SUS: Acolhimento com avaliação e classificação de risco: um paradigma ético-estético no fazer em saúde/Ministério da Saúde, Secretaria-Executiva, Núcleo Técnico da Política Nacional de Humanização. Brasília (DF): Ministério da Saúde; 2004

16. Brasil. Ministério da Saúde (BR). Secretaria de Atenção à Saúde. Núcleo Técnico da Política Nacional de Humanização. Acolhimento nas práticas de produção de saúde / Ministério da Saúde, Secretaria de Atenção à Saúde, Núcleo Técnico da Política Nacional de Humanização. 2a. ed. Brasília (DF): Ministério da Saúde; 2006.

17. Motta MG. Cuidado humanizado no ensino de Enfermagem. Rev Bras Enferm (DF) 2004;57(6):758-60.

18. Reibnitz KS. Profissional crítico-criativa em Enfermagem: a construção do espaço interseçor na relação pedagógica. Rev Bras Enferm 2004; 57(6):698-702. 